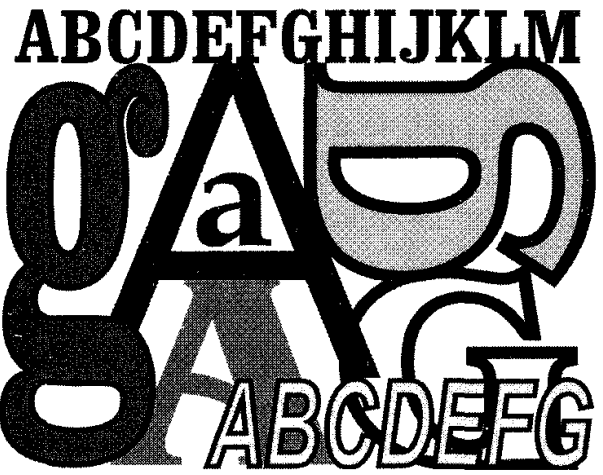

\title{
El origen del español en América
}

Cristina Simón

INTRODUCCIÓN AL TEMA: UN POCO DE HISTORIA

T a debatidísima cuestión acerca de la base o los orígenes (el nivel diatópico) del español en nuestro continente desde el comienzo mismo de sus planteamientos en el siglo pasado y, más concretamente, en las primeras décadas del presente, ha sido siempre polémica y no ha terminado todavía; no obstante, se ha llegado a ciertos acuerdos básicos entre un importante número de estudiosos sobre el tema.

Grosso modo, puede decirse que hay una confrontación básica en torno a este nivel de discusión, sobre la que trataré en líneas posteriores: la de los andalucistas y la de los antiandalucistas.

Sin embargo, antes de entrar de lleno en el tema, es necesario dilucidar si, en efecto, existe un español americano que, como tal, pueda oponerse al español peninsular visto, asimismo, como un ente homogéneo.

Pero vayamos por partes.

La reflexión sobre la existencia o no de un español americano, para muchos lingüistas, arranca a principios de nuestro siglo con Rufino José Cuervo quien, a lo largo de su amplísima producción, elaboró un primer cuadro de conjunto de las características del español en América. En un principio Cuervo, al igual que Bello, consideró al español peninsular como el único modelo de lengua culta pero, después de años de estudio y de minuciosas reflexiones, se convirtió en el verdadero fundador de la disciplina como un ente aparte dentro de la filología romance. Como señala Fontanella, ${ }^{1}$ dicha exposición posee una perspectiva histórica, quizás la primera articulación básica de toda la historia hispanoameri- 
cana, que sólo en parte ha sido superada con las aportaciones de otros muchos estudiosos.

Sin embargo, lingüistas como el doctor Moreno de $\mathrm{Alba}^{2}$ sugieren que se puede ir mucho más atrás y señalan la primera historia del español -Origen y principios de la lengua castellana - de Bernardo de Alderete en 1606 como la primera obra en la que se hace ya una reflexión comparativa entre el español europeo y el trasplantado a las colonias de ultramar.

No obstante la fijación de los límites temporales para el inicio de las reflexiones sobre el español transpeninsular, es un hecho que lo que se conoce como el "español en América" no pudo haber hecho su aparición sino hasta el siglo xIX cuando surgen los movimientos independentistas en nuestro continente, mismos que nos llevarían a romper la tutela con la metrópolis en muchos aspectos incluido, por supuesto, el de la lengua que hablamos.

Pero, ¿existe o no un español americano? Para tratar de responder a este cuestionamiento, me parece interesante transcribir las palabras que el doctor J.M. Lope Blanch pronunció en su ponencia -Fisonomía del español en América: Unidad y diversidad - en el primer Congreso Internacional sobre el Español de América que se llevó a cabo en San Juan de Puerto Rico en octubre de 1982, ${ }^{3}$ ya que creo que su observación es aún válida en este momento de la discusión sobre el asunto:

Para este extraordinario congreso, $[\ldots]$, me ha parecido adecuado e inclusive - tal vez- oportuno comenzar por el principio, es decir, prestando atención al primer y esencial problema que el español de América plantea: el de su existencia misma como una modalidad de la lengua española. Sospecho y aun temo que a muchos de ustedes, si no es que a todos, pueda parecerles superflua o incluso impertinente la atención que deseo prestar a ese problema, el cual acaso consideren ya totalmente superado, y del cual, sin duda, cada uno tiene su propia opinión. Mas me atrevo a suponer que tal problema no está todavía enteramente resuelto y que, por ello, no faltarían entre ustedes opiniones verdaderamente encontradas en lo que a su solución respecta.

Esta cita nos puede ubicar en lo intrincado del problema -primero y esencial- aún en nuestros días, después de casi un siglo de discusiones y reflexiones

${ }^{2}$ Moreno de Alba, J.G., 1993, El español en América, México: FCE.

${ }^{3}$ Tomado de Lope Blanch, J.M., 1989, “Fisonomía del español en América: Unidad y diversidad", en Estudios de lingüistica hispanoamericana, México: UNAM. 
en torno al mismo. En efecto, el punto de partida arranca con la polémica que, en la década de los veinte, mantuvieron los lingüistas Max Wagner y Henríquez Ureña; a partir del establecimiento de estas posturas, las discusiones entre los estudiosos del tema se podrían agrupar en dos primeros grandes grupos:

a) La de quienes han afirmado que sí existe un español americano, entre los que se hallan el propio Max Wagner y Alonso Zamora Vicente y, en la actualidad, los lingüistas estadounidenses G. Cotton y John Sharp.

Sólo a modo de mención, me parece importante decir que esta postura ha sido claramente superada con sólidos argumentos por la mayoría de los estudiosos sobre el tema, excepto por los estadounidenses arriba mencionados quienes con poco conocimiento de causa y muy superficialmente se han adscrito a los planteamientos de Max Wagner.

b) La de quienes han sostenido que es imposible hablar del español americano como un ente sin fisuras. Entre ellos, destacan por sus planteamientos, autores como el mencionado Henríquez Ureña, quien una vez concluida la polémica sostenida con Max Wagner, es el primero en sustentar que el español americano no es una variedad dialectal, sino una entidad multiforme y variada; José Rona y el ya citado J.M. Lope Blanch, que tras años de minuciosas investigaciones sobre el tema se adscriben a lo dicho por sus antecesores.

En efecto, en una visión panorámica de las posibles características del habla americana, sólo podemos considerar los siguientes rasgos como exclusivos, pero no generales, por lo que, afirmar que existe un español americano como un bloque totalmente homogéneo y sin fisuras es tan aberrante como afirmar que exista un español peninsular igualmente homogéneo. Dichos rasgos son:

-En el plano de la morfosintaxis: Voseo, desaparición del pronombre personal de segunda persona plural -vosotros/as - con el consiguiente reajuste del paradigma verbal y el uso particular de la preposición hasta con valor temporal restrictivo en ciertas zonas.

-En el plano fonológico: Seseo, yeísmo y zeísmo, la aspiración de /-s/ final, la realización aspirada de /x/y las distintas realizaciones de /-r/ y /-1/.

-En el plano léxico: El español americano presenta varias diferencias, pero no sólo con respecto al español peninsular, sino entre las diversas regiones 
americanas. Estas diferencias se refieren, tanto a la vigencia de términos patrimoniales como a indigenismos. De cualquier manera, dichas diferencias no afectan al vocabulario básico del español general.

Además de lo expuesto hasta este momento, es necesario agregar que, en la dilucidación de esta cuestión, tampoco se puede perder de vista ni olvidar el carácter complejo y variado del proceso de trasplante del español a América, ni sus repercusiones lingüísticas, dado que existen diferencias sustanciales entre las regiones de poblamiento temprano y las más tardías, en la inteligencia de que el español implantado no tenía, ni mucho menos, las mismas características conformadoras. Pensemos en los rangos temporales tan largos que median entre las conquistas de los diferentes lugares: Antillas (1492), México (1521), Panamá (1519), Perú (1532), Cartagena (1533), Venezuela (1547), Bolivia (1550), Argentina y Chile (mediados del XVI, pero cuyas conquistas no se consuman hasta mediados del XVII), Paraguay y Uruguay (principios y mediados del xVII).

Asimismo, hay que tener en cuenta las regiones de poblamiento directo a partir de España, de las de la propia expansión americana; los distintos tipos de relación con la metrópoli, etcétera.

Con base en lo expuesto hasta el momento, podríamos llegar a una primera conclusión y afirmar que no se puede hablar de un español americano - de la misma manera en que tampoco puede hacerse de un español peninsular - y que se entiende por español americano una entidad lingüística $-\mathrm{y}$ desde luego también cultural- que se puede definir geográfica e históricamente. ${ }^{4}$

\section{ORIGEN DEL ESPAÑOL EN AMÉRICA}

\section{Generalidades}

Hasta el momento no hay todavía una obra de conjunto sobre el español de América, pero sí varios estudios serios sobre diferentes aspectos determinados y concretos. Éstos han tenido diferentes abordajes, según los momentos en los que ocurrieron y las posturas asumidas por sus autores. A este respecto, me permito nuevamente recurrir a las palabras del doctor Lope Blanch: ${ }^{5}$

La imposibilidad de emprender, todavía hoy, estudios generales - precisos y rigurosos- sobre el "español de América" obedece, fundamentalmente, a dos circunstancias; una, a la carencia de estudios particulares

${ }^{4}$ Vide Beatriz Fontanella, Op. cit. sobre todo las pp. 14-15.

${ }^{5}$ Lope Blanch, J.M., 1989, "Los estudios generales", en Op. cit. 
sobre un elevadísimo número de poblaciones o de regiones hispanoamericanas; otra, a la ligereza y superficialidad con que se han estudiado, en no pocas ocasiones, las diversas modalidades del español hablado en América. Sin una labor de análisis múltiple, resulta imposible hacer la labor de síntesis $[\ldots]$

Sin embargo, tanto el doctor Lope Blanch, como otros estudiosos serios del tema, coinciden en que ha habido reflexiones sobre aspectos concretos de este magno tema que han tenido buen éxito y que han logrado llegar, en líneas generales, a un cierto concenso. Uno de estos aspectos es precisamente el debatidísimo problema de los orígenes del español americano. En cuanto a él, y siguiendo la sistematización propuesta por Fontanella, ${ }^{6}$ se puede hablar de tres etapas más o menos definidas en torno al problema que nos ocupa:

I. Desde el inicio de las reflexiones sobre el tema hasta los años sesenta, la mayoría de las reflexiones giraron en torno al origen de los fenómenos más característicos del español americano. Dentro de este enfoque, tres han sido las principales posturas:

\section{Teorías sustráticas}

Rodolfo Lenz sostuvo que los rasgos característicos del español chileno se debían a la influencia del sustrato de las lenguas indígenas. ${ }^{7}$ Este abordaje es comprensible, si pensamos que, a fines del siglo xIx, las teorías sustráticas de Ascoli, ${ }^{8}$ aplicadas a la expansión del latín, alcanzaron gran importancia en Europa. En nuestro continente el español, dado que éste - como el latín - había sido una lengua transplantada y superpuesta a otras habladas previamente por la población sometida, reunía todas las características para aplicar el enfoque de Ascoli y de sus seguidores.

El primer enfoque vertido en estudios concretos son los hechos por el ya mencionado Lenz sobre el español en Chile, en donde el lingüista alemán señala reiteradamente el influjo del araucano sobre el español - el español de Chile, "es principalmente español con sonidos araucanos"-, tesis a la que llega después de describir los sistemas fonológicos de ambas lenguas y señalando más de diez rasgos, a su juicio, que distinguen el español chileno del resto de las realizaciones americanas.

${ }^{6}$ Op. cit. pp. 25-54.

7 Wagner, M.L., 1949, Lingua e dialletti dell'America Spagnola. Florencia. Citado por Fontanella y Lope Blanch en $O p$. cit.

${ }^{8}$ Véase, a este respecto, el imprescindible estudio: Tagliavini, Carlo, Orígenes de las lenguas neolatinas, México: FCE. 
Con todas las deficiencias - producto de los conocimientos alcanzados hasta aquella época- de su propuesta, ésta alcanzó muy buena acogida entre los hispanistas extranjeros, principalmente alemanes, como Meyer-Lübke, quien concuerda plenamente con su colega y utiliza sus pasos para establecer un parangón con la influencia de las lenguas de sustrato con el latín, y Max L. Wagner que, aunque discute ciertos aspectos de los planteamientos de Lenz, concuerda con él.

En el mundo hispánico, su propuesta fue recibida con mayores recelos y dividió a los lingüistas en dos bloques:

a) Autores como Menéndez Pidal y Rufino J. Cuervo manifestaron desde el principio sus reservas.

b) Autores como Henríquez Ureña, ${ }^{9}$ que se adscribió a ella y consideró esta teoría sustrática como básica en la conformación de las distintas variedades del español americano. De hecho dividió, provisionalmente ${ }^{10}$ en cinco las zonas dialectales, dependiendo éstas del contacto con alguna de las lenguas indígenas principales, a saber: náhuatl, maya, quechua, araucano y guaraní. Las zonas son: México, la región del Caribe, la andina, Chile y la región rioplatense, tomando en cuenta los siguientes elementos como causantes de esta diferenciación:

-proximidad geográfica de las regiones que lo componen

-lazos políticos y culturales que las unieron durante la dominación española

Angel Rosenblat, ${ }^{11}$ discípulo y continuador en muchos aspectos de Ureña, aceptó asimismo la tesis sustrática, aunque fue matizándola en sus reflexiones posteriores, señalando que la influencia de las lenguas indígenas es apenas perceptible en la mayor parte del continente y que el español no ha sido base en ninguna región americana de lenguas criollas como ha ocurrido con el portugués, el francés o el inglés, afirmación ésta que se ha visto rebatida por investigaciones más recientes. ${ }^{12}$

${ }^{9}$ Henríquez Ureña, P., 1921, Observaciones sobre el español de América, RFE. 7.

${ }_{10}$ Sin embargo, a pesar del calificativo de provisional, estudiosos de la materia como el doctor Moreno de Alba consideran que esta división, por su sencillez y claridad frente a las complejas divisiones propuestas posteriormente por autores como Rona -El problema de la división del español en zonas dialectales, entre otras-- sigue siendo válida en líneas generales.

"Rosenblat, A., 1967, "Contactos interlingüísticos en el mundo hispánico: el español y las lenguas indígenas de América", en Actas del Segundo Congreso Internacional de Hispanistas, Nimega.

${ }_{12}$ A este respecto, véase, tanto por la excelente ponencia como por la extensa bibliografía propuesta: De Granda, G., 1986, "Situación actual de los estudios lingüísticos afrohispanoamericanos" en Actas del II Congreso Internacional sobre el español de América, México: UNAM. 
Como señala Fontanella, tanto los planteamientos de Henríquez Ureña como los de Roseblant y otros autores que se adscribieron a esta teoría son explicables en el devenir de los estudios lingüísticos; sin embargo, lo que es ciertamente incomprensible para ella es el hecho de que en nuestros días, lingüistas como Cotton y Sharp - Spanish in the Americas - sigan "superficialmente aferrados a este tipo de explicaciones minimizadoras de la realidad lingüística americana".

Un grupo de lingüistas se ha dedicado a refutar este tipo de tesis sobre el peso del sustrato en la conformación del español americano. Autores de la talla de Amado Alonso, ${ }^{13}$ Bertil Malmberg, quien se apoyó en un riguroso enfoque estructuralista y como señala Fontanella, reflexionó sobre el tema durante más de una década -1948-1964-, Marcos Morínigo o Berta Vidal se han encargado de refutar los planteamientos de Lenz, mediante un análisis profundo de sus planteamientos.

A modo de conclusión sobre este punto, se puede decir, parafraseando a Beatriz Fontanella en acuerdo con la mayoría de los estudiosos serios sobre el tema que, en estos momentos, es ya injustificable atribuir al sustrato las particularidades lingüísticas del español americano. Para la mayoría de los lingüistas actuales, es la consideración general sociolingüística la que debe prevalecer en este tipo de estudios y análisis.

\section{2 y 3. La teoría andalucista y la posición poligenética}

Como el español americano es una lengua trasplantada, es esperable que las características dialectales del habla de los colonizadores hayan incidido en la configuración lingüística de la región de expansión. En este caso concreto, las similitudes entre el español de las distintas regiones de América y de Andalucía fueron ya señaladas desde el periodo colonial.

Además de la obra de Alderete mencionada ya en el presente artículo, a fines del xvir el obispo Piedrahita señala las primeras semejanzas entre el español americano y el andaluz, en su obra Historia general de las conquistas del Nuevo Reyno de Granada (Amberes, 1688) y, posteriormente Antonio de Salcedo en su Diccionario histórico-geográfico de las Indias Occidentales o América (Madrid, 1789) alude al origen andaluz de ciertas peculiaridades léxicas americanas, por lo que añade a dicha obra un apéndice al que denominó Vocabulario de las voces provinciales de América. ${ }^{14}$

${ }^{13}$ Alonso, A., 1939, Examen de la teoría indigenista de Rodolfo Lenz, RFE, I.

${ }_{14}$ Citados por Guitarte, L. Guillermo, 1991, Siete estudios sobre el español de América, México: UNAM y también por Beatriz Fontanella en $O p$. cit. 
En el presente siglo, el problema ha sido abordado desde una diferente perspectiva que le ha otorgado mayor rigor a los planteamientos; la teoría andalucista ocasionó una de las más encendidas polémicas.

El detonante fue un artículo publicado por Max L. Wagner en $1920^{15}$ que sostiene que la influencia de los dialectos sudespañoles - andaluz y extremeñoen el español americano es un hecho comprobable.

En un artículo posterior -1927-, Wagner amplió el término andalucismo al de "español meridional" y lo aplicó a las tierras bajas de América: las Antillas, las costas atlánticas de México y Colombia, el litoral de Venezuela, Chile y Río de la Plata; insiste, desde luego, en el influjo meridional, destacando los rasgos compartidos:

-Articulación predorsal de la $s$

-Relajación de las consonantes finales, sobre todo de la $-s$

-Aspiración, nasalización o vocalización de la $-r$ final de sílaba. ${ }^{16}$

Contra esta teoría, en los mismos años veinte y treinta; primero, y en los cincuenta después, aparece la propuesta poligenética sostenida por Henríquez Ureña.

En 1921, el filólogo dominicano publicó sus Observaciones sobre el español en América (RFE, VIII, 1921), en la que negaba la idea del supuesto andalucismo general en América, restringiéndolo a las tierras bajas. El filólogo dominicano se basó en la autoridad indiscutible del maestro Cuervo a quien presentó como el primer antiandalucista y afirmó que el padre de la filología americana estaba en lo justo cuando aseveró, en 1901, que toda la península aportó su influencia dialectal para la conformación del español ${ }^{17}$ americano y restringió el término andalucismo a una semejanza entre este dialecto y los hablados en las tierras bajas americanas, aunque no debida a una importación del andaluz, sino a un desarrollo paralelo de todos ellos. Henríquez Ureña continuó reforzando sus argumentos durante toda la década de los veinte y, ya para los treinta, publicó su célebre Comienzos del español en América, en el que quiso zanjar la cuestión tratando de establecer más ampliamente lo que había hecho Cuervo con anterioridad, a saber: la procedencia regional de los españoles que llegaron a América a fines del siglo xvi.

Con los métodos y la información disponible en su época, concluyó que sólo el $42.5 \%$ de los españoles venidos a estas tierras eran meridionales, por lo que no pudieron ser ellos los impositores de las características del habla americana.

${ }^{15}$ Como señala Moreno de Alba - Op. cit.-, esta polémica representa el verdadero inicio de los estudios del español en América.

${ }^{16}$ Wagner, M. L., 1927, El supuesto andalucismo de América, en RFE, 14.

${ }^{17}$ El subrayado es mío, dada la importancia de esta afirmación para la conclusión final del presente artículo. 
Esta idea predominó con fuerza en el Instituto de Filología de Buenos Aires, entonces bajo la dirección de A. Alonso quien coincidía con estas tesis.

No obstante, Guitarte ${ }^{18}$ afirma que Cuervo no fue antiandalucista, sino que H. Ureña lo interpretó de manera desviada. El pasaje que originó la tergiversación de Ureña - "Toda la península dio su contingente a la población de América" - aparece en la obra de Cuervo titulada El castellano en América que se publicó en 1901 en el Bolletin Hispanique.

Lo que es muy interesante es el hecho de que Cuervo excluye toda posibilidad de influencia andaluza superior al porcentaje mínimo de localismos que hay que conceder a todo colono, y considera los rasgos peculiares del español americano como debidos a una "evolución espontánea" y no a transplante de regionalismos peninsulares.

Evidentemente, para el filólogo colombiano, el español americano no es un simple transvase del peninsular, sino que es "el precipitado del "cruce y mezcla' de las diferencias dialectales y sociales del conglomerado hispano que se estableció en el Nuevo Mundo".

En diversas ocasiones, Cuervo insiste en la idea del español americano como una coiné ${ }^{19}$ americana surgida de la nivelación ${ }^{20}$ de la lengua de los primeros colonos. Unas veces lo considera como "resultante", otras, como "término medio" pero, sea como fuere, el hecho es que Cuervo se explicaba así la formación de la base del español de América y nunca participó de la opinión que identificaba lingüísticamente a Andalucía con la América hispánica.

Finalmente, hay que mencionar que para Guitarte, Cuervo puede caracterizarse como andalucista en los planos:

1. Léxico: ya que él consideraba que, as la nivelación del habla en América, quedaron bastantes vestigios léxicos andaluces, y que en la coiné resultante se generalizó por lo menos un provincialismo debido a los colonos de Andalucía.

Sin embargo, ante la inexistencia de un buen diccionario de andalucismos, no se puede verter luz en este espinoso tema.

2. Fonético: la extensión de ciertos fenómenos como:

\footnotetext{
${ }^{18}$ Op. cit. pp. 11-31.

${ }^{19}$ Coiné o koiné: resultado estabilizador de la mezcla de subsistemas lingüísticos, tales como dialectos regionales o literarios.

${ }_{20}$ Nivelación: Reducción, consciente o no, de elementos heterogéneos de una misma lengua para lograr una determinada homogeneidad. Puede realizarse en cualesquiera de los tres planos de la lengua: fonético, morfológico o léxico.
} 
-El seseo, rasgo impuesto a todo el español americano por los andaluces: la confusión de las sibilantes ç, z, ss y s.

- La aspiración de la $\mathrm{h}$ proveniente de $\mathrm{f}$.

Ambos fenómenos pertenecen al fondo originario del español americano, ya que ocurren en la lengua durante los primeros tiempos de la conquista y se pueden haber producido por la concurrencia y cruzamiento de las diversas hablas de la metrópoli, renuentes muchas a aceptar una sola forma de pronunciación; de esta manera, los descendientes de los primeros colonizadores se igualaron adoptando la más común. Éstos, como se señaló antes, son fenómenos generales en toda la América hispánica.

Ahora bien, en cuanto a los fenómenos fonéticos de conversión de $l l$ en $y$ (yeísmo) y el desvanecimiento de $-d-$ en las terminaciones en $-a d o-$ el filólogo colombiano opinaba que no eran efecto de la influencia andaluza o española en general - ya que el fenómeno se repite en casi toda la península - sino efecto de una evolución espontánea en ambas orillas.

En efecto, parece que las dos alteraciones no ocurren en España sino hasta el siglo xviII, momento en el que las sociedades americanas ya estaban constituidas, razón que elimina la posibilidad de que estos fenómenos se hayan implantado entonces. Además, es un hecho que la difusión de estos fenómenos no es uniforme ni general en la América hispánica.

Lo que es importante destacar del pensamiento del maestro Cuervo es su enorme intuición y certera mirada en todos los aspectos de reflexión del español americano.

Asimismo, es importante señalar, como lo hace Guitarte ${ }^{21}$ que la obnubilación de Henríquez Ureña en cuanto a su rechazo del andalucismo en el español americano tiene un fuerte sustento histórico. Alude a la constitución, en 1910, de El Ateneo de la Juventud en México: José Vasconcelos, Antonio Caso, Alfonso Reyes, Martín Luis Guzmán y el propio Henríquez Ureña, que tomaron como uno de sus baluartes el pensamiento de Justo Sierra.

La pretensión general del movimiento era otorgar a la América hispánica el lugar que le correspondía en la historia de occidente por sí misma (originalidad americana) y no como mera réplica o remedo de la cultura española, además de señalar el enorme espectro de diferencias que existen en las comunidades hispanoamericanas, tratando de romper la idea generalizada de la similitud de dichas comunidades.

Las ideas principales que integran la concepción de la autoctonía americana del maestro dominicano son:

${ }^{21}$ Guitarte, "La oposición de Henríquez Ureña al Andalucismo de América", en Op. cit., pp. 38-56. 
1. Intuición del distinto carácter de lo hispánico americano y de lo hispánico europeo.

2. Explicación genérica del origen de esta diferencia: modificación del espíritu español en América por causa del medio.

3. Intento de mostrar históricamente el proceso de diferenciación ya realizado desde fines del siglo xvI.

No hay que olvidar que Henríquez Ureña comienza su vida intelectual con una tesis sobre Juan Ruiz de Alarcón, en la que tratará de probar la mexicanidad del dramaturgo, ya desde el xviI.

Dice Guitarte que partiendo de estas mismas tesis literarias, y trabajando con la pasión más que con la razón, Ureña quiso hacer extensivo su pensamiento al campo de la filología, con el resultado de su mala interpretación sobre las ideas de Rufino Cuervo.

Sin embargo, aunque las aportaciones del maestro dominicano y de los demás seguidores de la teoría poligenética hayan sido importantísimas en el seguimiento del problema, fueron trascendidas en menos de una década por la aparición de varios trabajos fundamentales que vuelven a reafirmar la tesis andalucista:

Por una parte, los de Peter Boyd-Bowman ${ }^{22}$ que probaban que la población colonizadora andaluza constituye más del 30\% entre 1493 y 1519 .

Diego Catalán, ${ }^{23}$ desde un punto de vista netamente lingüístico, también dará un vuelco a la polémica y la virará nuevamente al andalucismo. Catalán pone de manifiesto que tanto el seseo ${ }^{24}$ como el ceceo actuales provienen de la confusión de las cuatro sibilantes latinas, confusión que se había originado en Andalucía ya en el xv $-\mathrm{o}$ quizás antes- de manera que los seseantes eran amplia mayoría en la población sevillana de fines de aquel siglo, por lo que es muy probable que fueran seseantes la mayoría de los andaluces que se embarcaron hacia Canarias y América.

Ante la contundencia de estos estudios, las tesis poligenéticas sobre el seseo americano perdieron su vigencia.

Rafael Lapesa dedicó varios importantes estudios al mismo tema, concluyendo que "hoy no hay duda respecto al origen andaluz de algunos de los rasgos más peculiares de la pronunciación americana" que son:

\footnotetext{
${ }_{22}^{2}$ Boyd-Bowman, P., 1964, 1968, Índice geográfico de cuarenta mil pobladores españoles en América en el siglo XVI, t.1, Bogotá, t.2, México.

${ }_{23}$ Catalán, D., 1957, "El ceceo-zezeo al comenzar la expansión atlántica de Castilla”, en Boletín de Filología, XVI.

${ }^{24}$ Para este tema, es importantísima la reflexión de Guitarte: "Las supuestas tres etapas del seseo" en $O p$. cit., tanto por sus planteamientos como por la extensísima bibliografía revisada y comentada.
} 
-el más general, el seseo

-muy probablemente el yeísmo

-seguros, aunque no generales en América, la confusión de - $l$ y - $r$ finales, la aspiración de $-s$ final y la sustitución de $-j$ por $-h$ aspirada.

El gran filólogo Ramón Menéndez Pidal ${ }^{25}$ da una enriquecedora visión del tema. Analiza el problema de la relación entre el habla andaluza y la americana en el contexto más amplio de los distintos condicionamientos que hacen a la conformación de las diferentes variedades del español de América; señala la importancia política y cultural que adquiere Sevilla durante el xvI, gracias a la reconquista de Granada que duplica casi el anterior territorio andaluz y a la conquista americana que tiene a Sevilla por cabecera.

Simultáneamente a estos fenómenos históricos, se produce una fractura lingüística que aleja la pronunciación andaluza de la castellana; la situación redunda en la coexistencia de dos centros de difusión lingüística: Madrid por un lado y Sevilla por otro. El habla sevillana va a imponer su principal rasgo, el seseo, en las tierras de expansión, por lo que citando textualmente a Menéndez Pidal:

En la base de la lengua colonial no sólo está la norma general de la lengua común, sino también un dialecto particular de ésta destacado sobre los otros desde el comienzo del xvi; así, el español ultramarino recibió un marcado tinte andaluz al aceptar la simplificación fonológica del çeçeozezeo surgida en el reino de Sevilla.

A esta primitiva "base común" recibida por todo el territorio americano, seguirá una diferenciación determinada por la distinta comunicación con la metrópoli: las zonas costeras americanas más directamente conectadas con los puertos andaluces por la flota verán reforzados los rasgos coincidentes con Andalucía (aspiración de la $/-s /$, confusión de $/-r / \mid-l /$, aspiración de $/ x /$ y debilitamiento de $(d /)$, en tanto que las zonas interiores permanecerán al margen de estos cambios. Por último, los asientos de cortes virreinales recibirán, a través del flujo de funcionarios, letrados y literatos, las innovaciones surgidas en el ámbito cortesano madrileño.

\footnotetext{
${ }^{25}$ Menéndez Pidal, R., 1962, "Sevilla frente a Madrid. Algunas precisiones sobre el español de América", en Miscelánea homenaje a André Martinet, 3.
} 


\section{Menéndez Pidal concluye:}

La varia comunicación de los dominios coloniales con la metrópoli, así como el carácter de vida comercial, agrícola o urbana, nos explica la repartición de los varios tipos de habla hispano-americana, el popular más andalucista, el conservador y el cortesano.

Décadas después, Olga Cock, ${ }^{26}$ siguiendo las ideas de Menéndez Pidal, en el sentido de la comprobación -mediante el análisis de textos de la época- de que el seseo ya se había producido en Andalucía para el xv, con lo que se comprueba una vez más que el fenómeno llegó de la península y no se gestó en nuestras tierras como querían afirmar Henríquez Ureña y Amado Alonso.

Como señala Beatriz Fontanella, Boyd-Bowman, ${ }^{27}$ en posteriores análisis de cartas escritas por andaluces radicados en Veracruz, presentan no sólo abundantes confusiones de sibilantes, sino también los restantes rasgos comunes al habla andaluza (yeísmo, pérdida de $-s$ final, confusión o caída de $-l,-r$ y pérdida de sonoras intervocálicas) que también se creían posteriores al xv y el demostrar que ocurrieron antes termina por echar tierra a las apreciaciones poligenéticas del español americano.

Así pues y a modo de conclusión de este apartado, tomo la idea del maestro Guitarte quien considera que el problema del andalucismo en nuestro continente no ha sido ciertamente un problema, sino un seudoproblema, ya que constituye una discusión ajena al pensamiento crítico y nació tanto de generalizaciones sofísticas como de los sentimientos heridos por ellas: el único problema lingüístico es el problema histórico de cómo se constituyó el español de América. ${ }^{28}$

II. A partir de los setenta, con el trabajo de Olga Cock ${ }^{29}$ sobre la evolución de las sibilantes en el Nuevo Reino de Granada se inaugura una nueva época en los estudios del español americano, abandonándose el tema central de los orígenes, para pasar a la reflexión sobre la evolución de rasgos específicos en determinadas regiones americanas: morfológicos, fonológicos o sintácticos, basados en documentos de época y centrados en el seguimiento de un solo fenómeno en una sola época y mediante una rigurosa metodología lingüística.

\footnotetext{
${ }^{26}$ Cock, O., 1969, El seseo en el Nuevo Reino de Granada (1550-1650), Bogotá.

${ }^{27}$ Fontanella, Op. cit.

${ }^{28}$ Véase Alonso, A., 1953, "La base lingüística del español americano", en Estudios lingüistica. Temas hispanoamericanos, Madrid.

${ }^{29}$ Cock, Op. cit.
} 
III. La década de los ochenta y los noventa está abriendo una nueva época; si bien continúan los estudios específicos de la década anterior, están apareciendo otros generales sobre la evolución lingüística en diferentes regiones de América hispánica.

Este cambio de abordaje ha permitido, por una parte, que se tenga una visión más de conjunto de la evolución de los distintos rasgos en cada región y, por otra, que se pueda comparar la evolución de diferentes fenómenos en distintas regiones.

Después de lo expuesto y a modo de conclusión general sobre los orígenes del español en nuestro continente, me parece acertado hacer mías las reflexiones de Beatriz Fontanella que, en cierto sentido, coinciden con las del maestro Cuervo, y afirmar que, tanto la coinización como la estandarización ${ }^{30}$ han tenido un papel fundamental en la conformación de los rasgos generales del español americano, así como en las características específicas de sus diferentes variedades, lo que no significa que otros procesos también hayan incidido en ellos.

La coinización de toda la América hispánica explica la generalización de algunos procesos simplificadores a todas o a la mayor parte de las variedades del español americano, así como a la presencia de rasgos dialectales de diferente procedencia peninsular en todas sus variedades. En este sentido, se pueden mencionar las confluencias léxicas en casi todos los países hispanoamericanos de andalucismos: amarrar; leonismos: fierro; galleguismos: cardumen, entre otros muchos regionalismos peninsulares.

También, las diversas proporciones de hablantes de los distintos dialectos de la península, junto con la diferencia de las regiones que siguen en contacto con las variedades peninsulares — produciendo un reciclamiento de la coinización- y con otras características aisladas, condicionan asimismo diferencias en las variedades dialectales resultantes.

La estandarización es también otro factor que determina las diferentes configuraciones de cada variedad dialectal resultante; es decir, la etapa en la que ésta se ha producido, así como los diferentes grados de la misma alcanzados en cada región. De tal modo que las zonas de temprana y profunda estandarización —como México- se frenó en gran medida el desarrollo de rasgos considerados "vulgares", hecho contrario a las zonas de nula o tardía estandarización — como Paraguay—donde se observa un amplio desarrollo de aquellos rasgos. Por último, en las zonas intermedias - como en Buenos Aires- que, aun con estandarización más tardía que México, pero muy profunda, parecen haber asimilado en un primer momento esos rasgos vulgares para luego desechar gran parte de ellos.

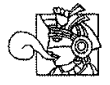

30 Estandarización: paso de un habla popular a variedad estándar. 


\section{BIBLIOGRAFÍA}

Alonso, A., 1939, Examen de la teoría indigenista de Rodolfo Lenz, RFE, I. , 1953, "La base lingüística del español americano", en Estudios lingüística. Temas hispanoamericanos, Madrid: Gredos.

Boyd-Bowman, P., 1964, 1968, Índice geográfico de cuarenta mil pobladores españoles en América en el siglo XVI, t.1, Bogotá, t.2, México.

Catalán, D., 1957, "El ceceo-zezeo al comenzar la expansión atlántica de Castilla", en Boletín de Filología, XVI.

Cock, O., 1969, El seseo en el Nuevo Reino de Granada (1550-1650), Bogotá. Fontanella de Weinberg, M.B., 1993, El español de América, Madrid: Mapfre. GRANDA, G. DE, 1986, "Situación actual de los estudios lingüísticos afrohispanoamericanos" en Actas del II Congreso Internacional sobre el español de América, México: UNAM.

Guitarte, L. Guillermo, 1991, Siete estudios sobre el español de América, México:UNAM.

HeNRíquez UReÑa, P., 1921, Observaciones sobre el español de América, RFE, 7. LoPE BlanCH, J.M., 1989, "Fisonomía del español en América: Unidad y diversidad", en Estudios de lingüística hispanoamericana, México: UNAM.

MenÉndez Pidal, R., 1962, "Sevilla frente a Madrid. Algunas precisiones sobre el español de América”, en Miscelánea homenaje a André Martinet, 3.

Moreno de Alba, J.G., 1993, El español en América, México: FCE.

Rosenblat, A., 1967, "Contactos interlingüísticos en el mundo hispánico: el español y las lenguas indígenas de América”, en Actas del Segundo Congreso Internacional de Hispanistas, Nimega.

Tagliavini, Carlo, Orígenes de las lenguas neolatinas, México: FCE.

WAGNeR, M. L., 1927, El supuesto andalucismo de América, en RFE, 14. 